\title{
Evaluation of Antioxidant Activity of Synthesized Silver Nanoparticles from Citrus Aurantium Peels Extract by Using the Green Method
}

\author{
Sumit Ringwal $^{1}$ • Ankit Singh Bartwal $^{1} \cdot$ S C Nautiyal $^{2} \cdot$ Satish Chandra Sati $^{1 *}$ \\ ${ }^{1}$ Department of Chemistry, H.N.B. Garhwal University (A Central University) Srinagar Garhwal, Uttarakhand, \\ India-246174 \\ ${ }^{2}$ Department of Physics, Govt. Degree College, Maldevta, Dehradun, India-248001 \\ *Corresponding Author Email Id: sati_2009@rediffmail.com
}

Received: 2.8.2021; Revised: 29.8.2021; Accepted:5.10.2021

(C)Society for Himalayan Action Research and Development

\begin{abstract}
The substance which avoids oxidant of easily oxidizing substance even at low concentration is called antioxidant when antioxidant reacts with reactive oxygen species (ROS) or reactive nitrogen species (RNS) they often convert themself into antioxidant radical. Although such a radical has a reduced ability to react with imperative cellular targets, it can still cause damage. To decrease reactivity and reduction potential further down, the 'antioxidant radical' react with another antioxidant and this reaction continues in a stepwise manner until antioxidant radical' is no longer damage the cells like lipids, protein, DNA, and other important cellular molecules. In this research article, we had scanned our previously synthesized silver nanoparticles from Citrus aurantium peels extracts; Synthesis and characterization part of the research work is already in communication we are extending our research work on previously synthesized silver nanoparticles. In this research article, we had scanned the antioxidant activity of synthesized AgNPs was determined by $\mathrm{H}_{2} \mathrm{O}_{2}$ free radical scavenging activity, we obtained antioxidant activity of BHT with $\mathrm{IC}_{50}$ Value $65.52 \mu \mathrm{g} / \mathrm{mL}$ and antioxidant activity of synthesized AgNPs with $\mathrm{IC}_{50}$ Value 93.92 $\mu \mathrm{g} / \mathrm{mL}$. Antioxidant activity of synthesized AgNPs was also determined by DPPH free radical scavenging activity. We obtained antioxidant activity of BHT with $\mathrm{IC}_{50}$ Value $65.99 \mu \mathrm{g} / \mathrm{mL}$ and antioxidant activity of synthesized AgNPs with $\mathrm{IC}_{50}$ Value $99.68 \mu \mathrm{g} / \mathrm{mL}$.
\end{abstract}

Keywords: Green method; Silver nanoparticle; Antioxidant activity; Citrus aurantium.

\section{Introduction}

Nobel metal nanoparticles especially silver nanoparticles have got great consideration in various fields of science and technology, due to its excellent utilization in various fields such as antimicrobial potential, environment remedy, chemical industry, photo-catalyst, drug delivery, and as biosensors (Wang et.al; 1991, Subbiah et.al; 2010). Additionally silver nanoparticles have several pharmacological applications like as antibacterial activity, anti-plasmodial activity, antifungal activity, anticancer, antiviral activity and antioxidant activity (Kuppusamy, et.al; 2016). In past few years antioxidant activity of silver nanoparticles is quite interesting to research topic for the scientific community due to their application in managing degenerative diseases.

Antioxidant agents which may be enzymatic or non-enzymatic materials regulate free radical, 
which is produced by various reactive oxygen species (ROS) or reactive nitrogen species (RNS).

The biological human body generates various free radicals inside our body to cure various diseases and antioxidant scavenged free radicals protect the damage of crucial bio-molecules. Antioxidants have a great advantage for the treatment of various unceasing diseases like diabetes, cancer, and brain dysfunction (Bhaumik et.al; 2015) sometimes antioxidants generated by our body may be insufficient to protect against various diseases so the human body needs the supply of antioxidants from outside. Alternatively silver nanoparticles show strong antioxidant potential than synthetic commercial antioxidants.

There are various methods which are reported for synthesis of silver nanoparticles (Khan et.at; 2011b, Chen et.al; 2007, Reicha et.al; 2012 , Abid et.al; 2012 , Khan et.al; 2011a , Alarcon, et.al; 2012), which include several physical and chemical methods but those methods are not safe for the environment due to hazardous and toxic side products obtained from those methods. So there is a great need for an eco-friendly method that does not harm the environment. Interestingly, the green methods have many advantages over other traditional methods (Krishnaraj et.al; 2010). There are various biological methods available for the synthesis of nanoparticle using bacteria, fungi, plant (Krishnaraj et.al; 2010). Several researchers have synthesized nanoparticle by using plant extract as reducing and capping agent (Sati et.al; 2020b).

Citrus aurantium is an evergreen tree, leaves are generally oblong, or eclipsed, 9-15 cm long, incised, base cuneate (leaf shape; narrowly triangular, wider at the apex and tapering toward the base.), apex acute or blunt. Flowers are found in terminal or axillary clusters of 4-9, and generally bisexual pinkish-white Stamens 20-30. Fruits oblong, slightly notched, $8-10 \mathrm{~cm}$ across rind thick, generally oblate, not mamillate, usually orange-colored, Pulp sweet, yellow, and rarely red (Gaur 1999, Anonymous 2001, Kirtikar et.al; 1918). In this study we have evaluated antioxidant activity of synthesized AgNPs by $\mathrm{H}_{2} \mathrm{O}_{2}$ and DPPH free radical scavenging activity this is the novelty of this research work.

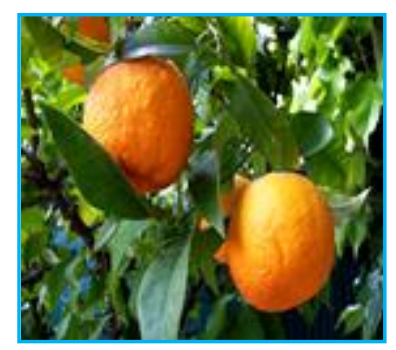

Fig.1: Fruits of Citrus aurantium

\section{Synthesis and Characterization}

We have synthesized silver nanoparticles from peels extract of Citrus aurantium on the basis of green chemistry principles [Bartwal et.al; 2020; Sati et.al; 2020a]. The brief synthesis protocol has illustrated in our previous article Sati et.al. 2020b. Characterization of synthesized AgNPs was done by several spectroscopic techniques 
like UV-Visible spectroscopy, X-ray diffraction method followed by SEM, EDAX, and TEM studies.

\section{Evaluation of antioxidant activity}

\section{DPPH free radical Scavenging Activity of synthesized AgNPs}

DPPH free radical Scavenging Activity of synthesized AgNPs was determined by the standard method (Cuendet et.al; 1997; Burits et.al., 2000). Five different concentrations of methanolic solution of the sample were added to $5 \mathrm{~mL}$ of a $100 \mu \mathrm{mol}$ methanolic solution of DPPH. After a $30 \mathrm{~min}$ incubation period at room temperature, the absorbance was read against a blank at $517 \mathrm{~nm}$. Inhibition of free radical DPPH in percent (I\%) was calculated using the formula presented in the literature (Kharat et.al; 2006).Assays were carried out in triplicate. Synthetic antioxidant butylated hydroxytoluene (BHT) was used as a positive control.

\section{Hydrogen Peroxide Radical Scavenging Activity}

Hydrogen Peroxide Radical Scavenging Activity of synthesized nanoparticles was determined by standard method (Thampi et.al; 2015). A solution of hydrogen peroxide $(40 \mathrm{mM})$ was prepared in phosphate buffer saline (at $\mathrm{pH}$ 6.8). Different concentrations of nanoparticles and nanocomposite $(20,40,60,80$, and $100 \mu \mathrm{g} / \mathrm{mL})$ were prepared, from each concentration $4 \mathrm{~mL}$ of the test sample was mixed with $0.6 \mathrm{~mL}$ of previously prepared $\mathrm{H}_{2} \mathrm{O}_{2}$ solution. The absorbance of the solution was measured at 230 $\mathrm{nm}$ after 10 minutes against blank solution using a UV-Vis spectrophotometer. At $230 \mathrm{~nm}$, the absorbance of hydrogen peroxide (control) was 2.698. Similarly free radical scavenging activity of aqueous extract of Citrus aurantium peels was done. Synthetic antioxidant butylatedhydroxytoluene (BHT) was used as a positive control. The percentage (\%) scavenging of $\mathrm{H}_{2} \mathrm{O}_{2}$ by the test samples was calculated. Each experiment was carried out in triplicates and the results were recorded as a mean or \% scavenging activity. The percentage of hydrogen peroxide scavenging by the test samples is calculated using the formula presented in the literature (Kharat et.al., 2016).

$$
\% \text { reduction }=\frac{A_{c}-A_{t}}{A_{c}} \times 100
$$

Where, $\mathbf{A}_{\mathbf{c}}=$ Absorbance of the control; $\mathbf{A}_{\mathbf{t}}=$ Absorbance of sample.

\section{Results and discussion}

Silver nanoparticles were fabricated by using green methods and Citrus aurantium peels extract was used as a stabilizing and capping agent. Synthesized AgNPs (silver nanoparticles) has been characterized by using different spectroscopic techniques like UV-Visible spectroscopy, X-RD, SEM, EDAX, and TEM. In UV-Visible absorption spectroscopy the peak was obtained at $465 \mathrm{~nm}$ which is characteristics peak for silver nano particles. Resulted XRD patterns confirm the cubic crystalline structure of AgNPs. The average grain size $9.5 \mu \mathrm{m}$ was observed by the SEM technique. The observed 
EDAX spectrum indicated peaks, for the presence of $\mathrm{Ag}, \mathrm{C}, \mathrm{O}, \mathrm{K}, \mathrm{Ca}$, and $\mathrm{Cl}$. The observed Ag peak may be originated from AgNPs,

\section{Antioxidant activity}

DPPH free radical scavenging activity of AgNPs

The antioxidant activity of synthesized AgNPs was determined by DPPH free radical scavenging activity taking a different concentration of silver nanoparticle solution that is $20,40,60,80$, and $100 \mu \mathrm{g} / \mathrm{mL}$. BHT solution was used as a positive control; the antioxidant activity of BHT and the antioxidant activity of synthesized AgNPs are shown in table 1. Obtained antioxidant activity of BHT with $\mathrm{IC}_{50}$ value $65.99 \mu \mathrm{g} / \mathrm{mL}$ [see Fig.2(a)] and antioxidant activity of synthesized AgNPs with $\mathrm{IC}_{50}$ value $99.68 \mu \mathrm{g} / \mathrm{mL}$ [Fig.2(b)].

Table 1: DPPH free radical scavenging activity of Standard (BHT) and AgNPs

\begin{tabular}{|c|c|c|c|c|c|c|}
\hline \multirow[t]{2}{*}{ S.No. } & \multirow{2}{*}{$\begin{array}{c}\text { Concentration } \\
(\mu \mathrm{g} / \mathrm{mL})\end{array}$} & \multicolumn{2}{|c|}{ Absorbance } & \multicolumn{2}{|c|}{$\%$ Reduction } & \multirow{2}{*}{$\begin{array}{c}\text { IC }_{50} \text { Valuc } \\
(\mu \mathrm{g} / \mathrm{mL})\end{array}$} \\
\hline & & Standard & AgNPs & Standard & AgNPs & \\
\hline 1 & 20 & 0.362 & 0.419 & 19.55 & 6.84 & \multirow{3}{*}{$\begin{array}{c}\text { Standard } \\
65.99\end{array}$} \\
\hline 2 & 40 & 0.336 & 0.397 & 25.33 & 11.77 & \\
\hline 3 & 60 & 0.252 & 0.341 & 44 & 22.81 & \\
\hline 4 & 80 & 0.172 & 0.270 & 62.00 & 40.00 & AgNPs \\
\hline 5 & 100 & 0.101 & 0.200 & 76.30 & 51.11 & 99.68 \\
\hline
\end{tabular}

It is observed that there is a significant change in the DPPH radical scavenging activity for studied samples. The scavenging capacity increased in a dose-dependent manner. The recorded \% reduction was found to be minimum at the lowest concentration that is at $20 \mu \mathrm{g} / \mathrm{mL}$, BHT reduced to $19.55 \%$ while when the concentration reaches $100 \mu \mathrm{g} / \mathrm{mL}$ BHT reduced upto $76.30 \%$.
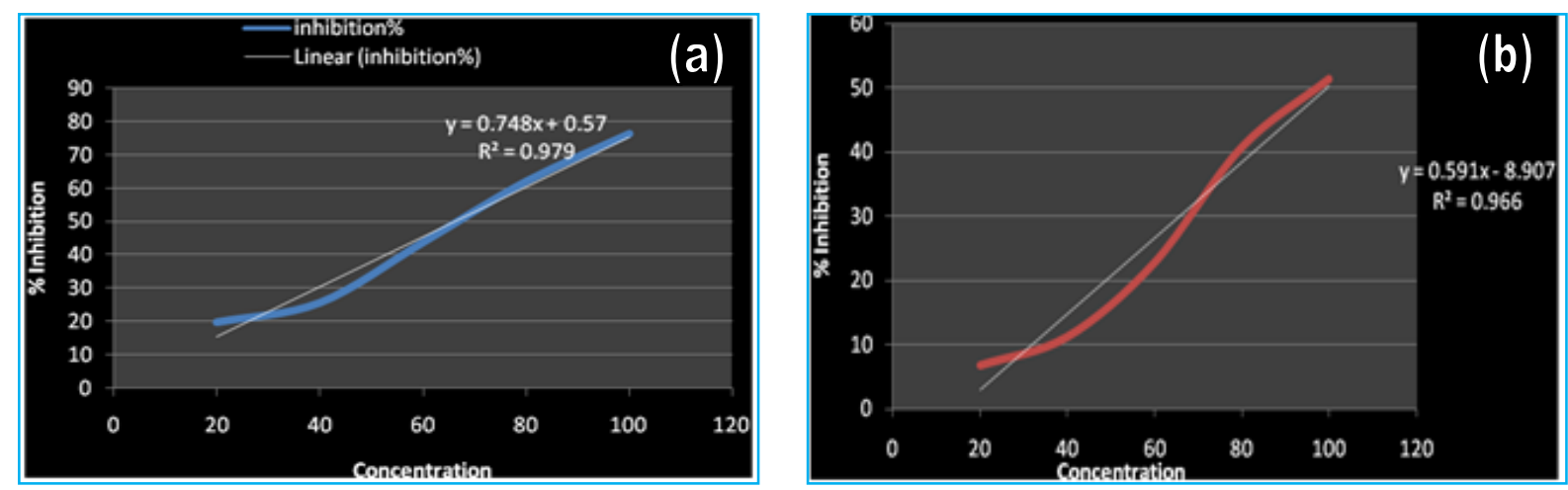

Fig.2: DPPH free radical scavenging activity of (a) BHT; (b) AgNPs 
Literature survey reveals that there is various research study carried by the researcher in the field of nanoscience especially on the medicinal plant but no report is available on antioxidant activity of synthesized silver nanoparticles from Citrus aurantium peels extract. But there is several research data available on antioxidant activity of orange varieties (Citrus sinensis L. and Citrus aurantium L.) cultivated in Algeria: peels and leaves (Lagha et.al., 2013).
$\mathrm{H}_{2} \mathrm{O}_{2}$ free radical scavenging activity of AgNPs from Citrus aurantium peels extract

The antioxidant activity of synthesized AgNPs was determined by $\mathrm{H}_{2} \mathrm{O}_{2}$ free radical scavenging activity taking a different concentration of silver nanoparticle solution that is $20,40,60,80$, and $100 \mu \mathrm{g} / \mathrm{mL}$. BHT solution was used as a positive control. Antioxidant activity of BHT and synthesized AgNPs are shown in table 2.

Table 2: $\mathrm{H}_{2} \mathrm{O}_{2}$ free radical scavenging activity of Standard (BHT) and AgNPs

\begin{tabular}{|c|c|c|c|c|c|c|}
\hline \multirow{2}{*}{ S.No. } & $\begin{array}{c}\text { Concentration } \\
(\boldsymbol{\mu g} / \mathbf{m L})\end{array}$ & \multicolumn{2}{|c|}{ Absorbance } & \multicolumn{2}{c|}{ \% Reduction } & \multirow{2}{*}{$\begin{array}{c}\text { IC }_{\mathbf{5 0}} \text { Value } \\
(\boldsymbol{\mu g} / \mathbf{m L})\end{array}$} \\
\cline { 3 - 6 } & & Standard & AgNPs & Standard & AgNPs & \\
\hline 1 & 20 & 2.224 & 2.390 & 17.62 & 11.48 & Standard \\
\hline 2 & 40 & 1.966 & 2.247 & 27.18 & 16.77 & $\mathbf{6 5 . 5 2}$ \\
\hline 3 & 60 & 1.483 & 1.963 & 45.07 & 17.29 & \\
\hline 4 & 80 & 1.022 & 1.456 & 62.14 & 46.07 & \multirow{2}{*}{ AgNPs } \\
\hline 5 & 100 & 0.620 & 1.163 & 77.03 & 56.92 & $\mathbf{9 3 . 9 2}$ \\
\hline
\end{tabular}
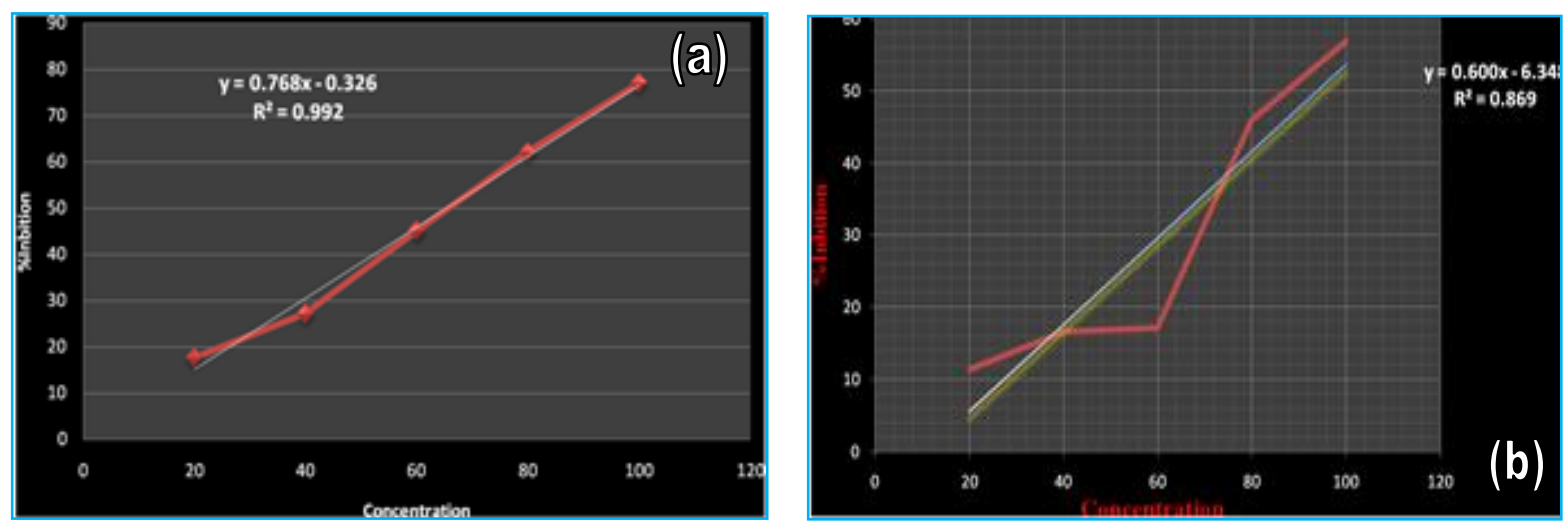

Fig.3: $\mathrm{H}_{2} \mathrm{O}_{2}$ free radical scavenging activity of (a) BHT; (b) AgNPs

We obtained antioxidant activity of BHT with $\mathrm{IC}_{50}$ Value $65.52 \mu \mathrm{g} / \mathrm{mL} \quad[$ Fig.3(a)] and antioxidant activity of synthesized AgNPs with $\mathrm{IC}_{50}$ Value $93.92 \mu \mathrm{g} / \mathrm{mL}$ [see Fig. 3(b)].

\section{Conclusion}

AgNPs has been synthesized by using peels extract of Citrus aurantium as a stabilizing and capping agent. Synthesized silver nanoparticles have been characterized by UV-Visible spectroscopy, X-RD, SEM, E-DAX, and TEM. In UV-Visible absorption spectroscopy the peak 
was obtained at $465 \mathrm{~nm}$ which is characteristics peak for silver nano particles. XRD result shows that the synthesized AgNPs have cubic crystalline structure. The average grain size of AgNPs was $9.5 \mu \mathrm{m}$, which was observed by the SEM technique. The EDAX spectrum shows the peaks, for the presence of $\mathrm{Ag}, \mathrm{C}, \mathrm{O}, \mathrm{K}, \mathrm{Ca}$, and Cl. Synthesized AgNPs from Citrus aurantium peels extracts has significant potential for an antioxidant activity like $\mathrm{H}_{2} \mathrm{O}_{2}$ free radical scavenging activity, we obtained antioxidant activity of BHT with $\mathrm{IC}_{50}$ Value $65.52 \mu \mathrm{g} / \mathrm{mL}$ and antioxidant activity of synthesized AgNPs with $\mathrm{IC}_{50}$ Value $93.92 \mu \mathrm{g} / \mathrm{ml}$. Antioxidant activity of synthesized AgNPs was also determined by DPPH free radical scavenging activity we obtained antioxidant activity of BHT with $\mathrm{IC}_{50}$ Value $65.99 \mu \mathrm{g} / \mathrm{mL}$ and antioxidant activity of synthesized AgNPs with $\mathrm{IC}_{50}$ Value $99.68 \mu \mathrm{g} / \mathrm{mL}$.

\section{Acknowledgment}

The authors are thankful to USIC Department, HNB Garhwal University for XRD, SEM and EDAX characterization of samples. This work is not funded by any funding agencies.

\section{References}

Abid, JP, Wark, AW, Brevet, PF \& Girault, HH (2002). Preparation of silver nanoparticles in solution from a silver salt by laser irradiation. Chemical Communications; (7), 792-793.
Alarcon, EI, Udekwu, K, Skog, M, Pacioni, NL, Stamplecoskie, KG, González-Béjar, M \& Scaiano, JC(2012). The biocompatibility and antibacterial properties of collagen-stabilized. photochemically prepared silver nanoparticles; Biomaterials; 33(19), 4947-4956.

Bartwal AS, Sumit and Sati SC (2020). Biosynthesis of silver nanoparticles from flowers of Rhododenderon campanulatum tree of Tungnath Himalaya; Applied Innovative research; 2: 39-43.

Bhaumik J, Thakur NS, Aili PK, Ghanghoriya A, Mittal AK \& Banerjee UC(2015). Bioinspired nanotheranostic agents: synthesis, surface functionalization, and antioxidant potential; ACS Biomaterials Science \& Engineering; 1(6), 382-392.

Burits, M \& Bucar, F(2000). Antioxidant activity of Nigella sativa essential oil; Phytotherapy research; 14(5), 323328.

Chen, P, Song, L, Liu, Y, \& Fang, YE(2007). Synthesis of silver nanoparticles by $\gamma$ ray irradiation in acetic water solution containing chitosan. Radiation Physics and Chemistry;76(7), 1165-1168.

Cuendet M Hostettmann, K Potterat O \& Dyatmiko W (1997). Iridoid glucosides with free radical scavenging properties 
from Fagraea blumei; Helvetica

Chimica Acta; 80(4), 1144-1152.

Gaur, RD (1999). Flora of the District Garhwal;

North West Himalaya;Transmedia.

Khan A, El-Toni AM, Alrokayan S, Alsalhi M,

Alhoshan M \& Aldwayyan AS (2011).

Microwave-assisted synthesis of silver nanoparticles using poly-Nisopropylacrylamide/acrylic acid microgel particles; Colloids and Surfaces A: Physicochemical and Engineering Aspects; 377(1-3), 356-360.

Khan Z, Al-Thabaiti SA, Obaid AY \& Al-Youbi AO (2011). Preparation and characterization of silver nanoparticles by chemical reduction method; Colloids and Surfaces B:Biointerfaces;82(2), 513-517.

Kharat SN \& Mendhulkar VD(2016). Synthesis, characterization and studies on antioxidant activity of silver nanoparticles using Elephantopus scaber leaf extract; Materials Science and Engineering $C$; 62, 719-724.

Kirtikar, KR \& Basu, BD (1998). Indian Medicinal Plants. Indian Medicinal Plants. 2nd ed. (I).

Krishnaraj C, Jagan, EG, Rajasekar, S, Selvakumar, P, Kalaichelvan, PT \& Mohan N. J. C. S. B. B(2010). Synthesis of silver nanoparticles using Acalypha indica leaf extracts and its antibacterial activity against water borne pathogens; Colloids and Surfaces B Biointerfaces; 76(1), 50-56.

Kuppusamy P, Yusoff MM Maniam, GP \& Govindan N(2016). Biosynthesis of metallic nanoparticles using plant derivatives and their new avenues in pharmacological applications-An updated report; Saudi Pharmaceutical Journal; 24(4), 473-484.

Lagha-Benamrouche, S \& Madani, K(2013). Phenolic contents and antioxidant activity of orange varieties (Citrus sinensis L. and Citrus aurantium L.) cultivated in Algeria: Peels and leaves; Industrial Crops and Products; 50, 723-730.

Pharmacopoeia, I (1996). Government of India, ministry of health and family welfare.Delhi: $\quad$ Controller of Publications; 2(35), 448.

Reicha FM, Sarhan A, Abdel-Hamid MI \& ElSherbiny IM(2012). Preparation of silver nanoparticles in the presence of chitosan by electrochemical method; Carbohydrate polymers; 89(1), 236244.

Sati SC, Kour G, Bartwal AS \& Sati MD (2020a). Biosynthesis of Metal Nanoparticles from Leaves of Ficus palmata and Evaluation of Their Antiinflammatory and Anti-diabetic Activities; Biochemistry; 59(33): 30193025. 
Sati SC, Sumit, Bartwal AS \& Agarwal AK (2020b). Green synthesis of silver nanoparticles from Citrus medica peels and determination of its antioxidant activity; Applied Innovative research; 2: 56-60.

Subbiah R, Veerapandian M \& S Yun, K (2010). Nanoparticles: functionalization and multifunctional applications in biomedical sciences; Current medicinal chemistry;17(36), 4559-4577.

Thampi, NIVETHA \& Shalini, JV (2015). Bioprospecting the in-vitro antioxidant and anti-cancer activities of silver nanoparticles synthesized from the leaves of Syzygium samarangense; Int. J. Pharm.Pharm. Sci; 7(7), 269-274.

Wang Y \& Herron N (1991). Nanometer-sized semiconductor clusters: Materials synthesis, quantum size effects; and photophysical properties; $J$ PhysChum, 95,525. 